\title{
Multipotent Mesenchymal Stem Cells From Adult Human Synovial Membrane
}

\author{
Cosimo De Bari, Francesco Dell'Accio, Przemyslaw Tylzanowski, and Frank P. Luyten
}

Objective. To characterize mesenchymal stem cells (MSCs) from human synovial membrane (SM).

Methods. Cell populations were enzymatically released from the SM obtained from knee joints of adult human donors and were expanded in monolayer with serial passages at confluence. Cell clones were obtained by limiting dilution. At different passages, SM-derived cells were subjected to in vitro assays to investigate their multilineage potential. Upon treatments, phenotypes of cell cultures were analyzed by histo- and immunohistochemistry and by semiquantitative reverse transcriptionpolymerase chain reaction for the expression of lineagerelated marker genes.

Results. SM-derived cells could be expanded extensively in monolayer, with limited senescence. Under appropriate culture conditions, SM-derived cells were induced to differentiate to the chondrocyte, osteocyte, and adipocyte lineages. Sporadic myogenesis was also observed. Five independent cell clones displayed multilineage potential. Interestingly, only 1 clone was myogenic. Donor age, cell passaging, and cryopreservation did not affect the multilineage potential of SM-derived cells. In contrast, normal dermal fibroblasts under the same culture conditions did not display this potential.

Conclusion. Our study demonstrates that human multipotent MSCs can be isolated from the SM of knee joints. These cells have the ability to proliferate extensively in culture, and they maintain their multilineage differentiation potential in vitro, establishing their progenitor cell nature. SM-derived MSCs may play a role in the regenerative response during arthritic diseases and

Supported by FWO grant G.0192.99.

Cosimo De Bari, MD, Francesco Dell'Accio, MD, Przemyslaw Tylzanowski, PhD, Frank P. Luyten, MD, PhD: Katholieke Universiteit Leuven, Leuven, Belgium.

Address correspondence and reprint requests to Frank P. Luyten, MD, PhD, Laboratory for Skeletal Development and Joint Disorders, Onderwijs \& Navorsing, Herestraat 49, 3000 Leuven, Belgium.

Submitted for publication November 3, 2000; accepted in revised form March 14, 2001. are promising candidates for developing novel cellbased therapeutic approaches for postnatal skeletal tissue repair.

Joint destruction represents the consequence of most inflammatory and degenerative rheumatic diseases, leading to severe functional disability. Their high prevalence and heavy impact on working capacity, coupled with the high costs of the therapeutic procedures, make joint diseases a major social issue.

Tissue damage results from an imbalance between two components, injuring factors (inflammatory/ immunologic, traumatic/mechanical) and reparative processes. So far, a great effort has been made to develop therapeutic approaches aimed at removing/ controlling the former component, but very little has been done to modulate the latter. In addition, patients with late-stage diseases are often seen in daily practice in rheumatology, when the tissue damage is already established. In these circumstances, tissue repair represents an important therapeutic goal. Regenerative medicine opens to the rheumatologist the opportunity not only to control the progression of diseases, but also, for the first time, to promote repair through tissue regeneration. This is a complex process of events encompassing cell differentiation and tissue patterning with architectonic organization. In this context, the use of the proper cell populations appears to be crucial for optimal tissue repair.

Stem cells are promising candidates for the regeneration of tissue and organ systems. Stem cells are generally defined as highly clonogenic cells capable of both self renewal and multilineage differentiation. During embryonic development, in a cascade of hierarchical events that remains to be elucidated, stem cells from the blastocyst give rise to cell progenies that become progressively restricted in their differentiation potential to eventually generate the specialized cells of the mature tissues (1). Increasing evidence supports the hypothesis 
that multipotent stem cells are available postnatally in different organs and tissues. These cells could contribute to postnatal growth and participate in tissue homeostasis by replacing differentiated cells lost to physiologic turnover, injury, and senescence.

Mesenchymal stem cells (MSCs) have the potential to differentiate into lineages of mesenchymal tissues, including cartilage, bone, fat, and muscle. Isolation and characterization of MSCs from bone marrow have been described (2). Indeed, marrow-derived cells seem to retain a remarkable plasticity, since they have much wider differentiation potential than previously thought. Marrow cells have been reported to contribute to angiogenesis $(3,4)$, somatic muscle development $(5,6)$, liver regeneration $(7,8)$, and the formation of central nervous system cell types $(9,10)$. Increasing evidence suggests that postnatal stem cells are not exclusive to bone marrow, but are also present in various tissues and organs. Periosteum is known to contain cells with chondro-osteogenic potential (11-13). Somatic muscle satellite cells, progenitors of myocytes and myotubes $(6,14)$, have been shown to contribute to the regeneration of the entire hematopoietic system in lethally irradiated mice (15).

In the present study, we characterized MSCs from human synovial membrane (SM). We show that SM-derived cells from adult human donors of various ages can be expanded in vitro over at least 10 passages, with limited cell senescence. We provide data demonstrating that SM-derived cells can be induced consistently into multilineage differentiation pathways in vitro, regardless of donor age. We prove that individual SMderived cell clones conserve this multilineage potential in vitro.

\section{MATERIALS AND METHODS}

Harvest of synovial tissue and isolation of the cells. Random biopsies of SM (wet weight 10-50 mg) were obtained aseptically from the knee joints of human donors of various ages (mean 41 years, range 18-65 years), either postmortem within 12 hours of death or at the time of surgical knee replacement for degenerative osteoarthritis. SM specimens were rinsed twice with Hanks' balanced salt solution (HBSS; Life Technologies, Merelbeke, Belgium) supplemented with antibiotic-antimycotic solution (100 units/ml penicillin, 100 $\mu \mathrm{g} / \mathrm{ml}$ streptomycin, and $0.25 \mu \mathrm{g} / \mathrm{ml}$ amphotericin B; Life Technologies), finely minced, and digested with $0.2 \%$ collagenase (Life Technologies) in high-glucose Dulbecco's modified Eagle's medium (DMEM; Life Technologies) containing 10\% fetal bovine serum (FBS; BioWhittaker, Verviers, Belgium) and antibiotics. Following overnight incubation at $37^{\circ} \mathrm{C}$, cells were collected by centrifugation, washed twice, resuspended in high-glucose DMEM supplemented with $10 \%$ FBS and antibiotics (growth medium), plated in a T25 culture flask, and allowed to attach for 4 days. Nonadherent cells were removed by changing the medium.

Cell expansion and cryopreservation. For expansion, cells were cultured in monolayer in growth medium at $37^{\circ} \mathrm{C}$ in a humidified atmosphere of $5 \% \quad \mathrm{CO}_{2}$. The medium was replaced every 3 days. After 10-25 days of primary culture, when the sparsely attached cells reached confluence, they were washed twice with calcium and magnesium-free phosphate buffered saline (PBS), harvested by treatment with trypsinEDTA (0.25\% trypsin, $1 \mathrm{~m} M$ EDTA; Life Technologies), and replated at a 1:4 dilution for the first subculture. Cell passages were continued in the same way with a 1:4 dilution when cells reached confluence. At passage 3 (P3), aliquots of trypsinreleased cells in DMEM with 20\% FBS and 10\% DMSO (Sigma, Bornem, Belgium) were cryopreserved in liquid nitrogen, thawed after variable times (range 3-24 months), replated, and expanded for the in vitro assays.

Cloning of SM-derived cells. Cell cloning was performed by limiting dilution. First passage SM-derived cells from a 42-year-old donor were suspended in growth medium at a density of $1 \times 10^{3} / \mathrm{ml}$. One hundred microliters of the cell suspension was plated in each well of the first row of a 96-well, flat-bottomed culture plate. Twofold dilution series were carried out in the adjacent wells throughout the plate. A total of 82 -fold dilution series were obtained. The following day, the well with the highest dilution that contained a single cell was identified within each series by careful microscopic examination. Cell populations arising from single cells in these wells were considered mono/oligoclonal and were subcultured as described above. Eight independent clones were obtained.

Senescence-associated $\beta$-galactosidase (SA- $\beta$-gal) staining. SA- $\beta$-gal staining was performed as described (16). At different passages during expansion, SM-derived cells from all donors were plated in chamber slides and allowed to attach in growth medium. Cells were washed in PBS, fixed for 5 minutes at room temperature in $3 \%$ formaldehyde, washed, and incubated overnight in a humid chamber at $37^{\circ} \mathrm{C}$ with fresh $\beta$-gal staining solution ( $1 \mathrm{mg} / \mathrm{ml} \mathrm{X-Gal} \mathrm{[Duchefa,} \mathrm{Haarlem,}$ The Netherlands], $40 \mathrm{~m} M$ citric acid/sodium phosphate [pH 6.0], $5 \mathrm{~m} M$ potassium ferrocyanide, $5 \mathrm{~m} M$ potassium ferricyanide, $150 \mathrm{~m} M \mathrm{NaCl}$, and $\left.2 \mathrm{~m} M \mathrm{MgCl}_{2}\right)$. Senescent human dermal fibroblasts were used as a positive control.

Telomerase activity. Telomerase activity was determined semiquantitatively in P3 SM-derived cells from all donors by the Telomerase polymerase chain reaction (PCR) enzymelinked immunosorbent assay (ELISA) kit (Roche Molecular Biochemicals, Brussels, Belgium), following the manufacturer's instructions. Briefly, lysates from $3 \times 10^{3}$ cells were used to perform the telomeric repeat amplification protocol (TRAP) assay (17). The substrate for telomerase was a biotin-labeled synthetic primer. The telomeric sequence was amplified by a 30-cycle PCR using a Perkin Elmer Thermal Cycler 9600 (Applied Biosystems, Lennik, Belgium). The biotinylated PCR product was semiquantified by ELISA. Absorbance was measured at $450 \mathrm{~nm}$, with a reference wavelength of $690 \mathrm{~nm}$. Samples were regarded as telomerase positive when the difference in absorbance was $>0.2 \mathrm{~A}_{450 \mathrm{~nm}}-\mathrm{A}_{690 \mathrm{~nm}}$ units. P3 human dermal fibroblasts and human embryonic kidney 293 cells were used as cell negative and positive controls, respec- 
tively. For a telomerase-negative control, 293 cell lysate was heat-treated prior to the TRAP reaction.

In vitro chondrogenesis. The in vitro chondrogenesis assay was performed as described elsewhere (13). After expansion in monolayer, SM-derived cells were released by trypsin treatment, counted, tested for viability by trypan blue exclusion, and resuspended in growth medium at a density of $2.0 \times$ $10^{7}$ viable cells $/ \mathrm{ml}$. Micromass cultures were obtained by pipetting $20-\mu \mathrm{l}$ droplets of cell suspension into individual wells of 24-well plates. After cells were allowed to attach without medium for 3 hours, a chemically defined serum-free medium (18) was added.

The day of plating in micromass culture was designated as day 0 . Starting on day 1 , when the culture medium was changed, recombinant human transforming growth factor $\beta 1$ (TGF $\beta 1$; R\&D Systems, Abingdon, UK) dissolved in $4 \mathrm{~m} M$ $\mathrm{HCl}$ containing $1 \mathrm{mg} / \mathrm{ml}$ bovine serum albumin (BSA; Serva, Heidelberg, Germany) was added to the culture medium every other day at a final concentration of $10 \mathrm{ng} / \mathrm{ml}$. Identical amounts of $4 \mathrm{mM} \mathrm{HCl}$ containing $1 \mathrm{mg} / \mathrm{ml} \mathrm{BSA}$ were added to parallel cultures as controls for the treatment. For a cell negative control, human dermal fibroblasts (kindly provided by S. Tejpar, Centrum Menselijke Erfelijkheid, Leuven, Belgium) were kept under identical conditions. After 6 days, micromass cultures were rinsed twice with PBS, fixed with methanol for 30 minutes at $-20^{\circ} \mathrm{C}$, washed with distilled water, and covered with Alcian blue (pH 0.2) (0.5\% Alcian blue 8 GS [Carl Roth, Karlsruhe, Germany] in $1 \mathrm{~N} \mathrm{HCl}$ ). After overnight staining, cultures were washed extensively with distilled water.

For histologic and immunohistochemical analysis, 100 $\mu \mathrm{l}$ of SM-derived cell suspensions was plated in micromass in individual wells of a 12-well plate. Micromasses were treated either with $10 \mathrm{ng} / \mathrm{ml}$ TGF $\beta 1$ or with the same amount of TGF $\beta 1$ carrier solution in the chemically defined serum-free medium. After 3 weeks, micromasses were peeled off the wells, fixed with $10 \%$ formalin, embedded in paraffin, and sectioned at $5 \mu \mathrm{m}$. For histologic evaluation, sections were deparaffinized and stained with Safranin O or toluidine blue according to standard protocols. For immunohistochemical analysis, after deparaffinization, sections were predigested with chondroitinase ABC (Sigma) at $50 \mathrm{mU} / \mathrm{ml}$ in PBS at room temperature for 1 hour to facilitate antibody access, then post-fixed in buffered $4 \%$ paraformaldehyde for 10 minutes at room temperature. Endogenous peroxidase was quenched by incubating the sections at room temperature in $3 \%$ hydrogen peroxide for 10 minutes. Nonspecific antibody binding was blocked by incubating the slides with normal goat serum (Dako, Glostrup, Denmark) diluted 1:5 in PBS containing 0.2\% Triton X-100 (Bio-Rad, Nazareth Eke, Belgium) for 20 minutes.

Sections were incubated for 30 minutes at room temperature with a mouse anti-human type II collagen monoclonal antibody (Chemicon International, Hofheim, Germany) diluted $1: 5$ in $0.5 \%$ BSA in PBS. Slides were then incubated for 30 minutes at room temperature with biotinylated goat antimouse IgG diluted 1:500 in 0.5\% BSA in PBS. The antibodybiotin conjugates were detected with a streptavidin-biotinhorseradish peroxidase complex (StreptABComplex/HRP; Dako) applied for 20 minutes at room temperature, using diaminobenzidine (Dako) as a substrate. Nuclei were counterstained with Carazzi's hematoxylin. Negative controls were sections of untreated micromasses incubated with primary antibody and sections of TGF $\beta 1$-treated micromasses incubated with normal mouse IgG (R\&D Systems) instead of primary antibody.

In vitro osteogenesis. The in vitro osteogenesis assay was performed as described elsewhere (19). SM-derived cells were plated in growth medium at $3 \times 10^{3} / \mathrm{cm}^{2}$ in 12 -well tissue culture plates. The following day, fresh growth medium was provided, and the cells were subsequently cultured for 4 weeks in the presence of $100 \mathrm{n} M$ dexamethasone, $10 \mathrm{~m} M$ $\beta$-glycerophosphate, and $50 \mu M$ ascorbic acid (all from Sigma). The osteogenic medium was changed twice a week. Controls for the osteogenic treatment were cells cultured in growth medium supplemented with vehicle solutions of the compounds of the osteogenic medium. For a cell negative control, human dermal fibroblasts were kept under identical conditions.

To determine alkaline phosphatase activity, cells were washed twice with PBS and disrupted by freezing at $-80^{\circ} \mathrm{C}$ for 20 minutes in $300 \mu \mathrm{l} /$ well of PBS containing $0.05 \%$ Triton $\mathrm{X}-100$. Aliquots of $20 \mu \mathrm{l}$ were assayed for enzyme activity using a commercially available kit (Kirkegaard \& Perry, Guildford, UK), according to the manufacturer's instructions. Protein content was determined with the Bradford protein assay (Bio-Rad), using BSA as standard. The experiment was performed in quadruplicate. Alkaline phosphatase activity was expressed as arbitrary units per microgram of protein content.

For histochemical analysis, cells were rinsed twice with PBS, fixed with $10 \%$ formalin for 10 minutes, and washed with distilled water. Alkaline phosphatase histochemistry was performed using the nitroblue tetrazolium/BCIP tablets (Roche Molecular Biochemicals), according to the manufacturer's instructions. Cultures were then rinsed with distilled water and air-dried prior to viewing. To stain calcium deposits, after fixation, cells were covered with alizarin red S solution $(2 \%$ aqueous solution [pH 4.2]; Sigma) for 3 minutes. Cultures were then washed thoroughly with distilled water.

In vitro myogenesis. The in vitro myogenesis assay was performed as described elsewhere (20). Briefly, SM-derived cells were seeded into $35-\mathrm{mm}$ dishes at a density of $5,000 / \mathrm{ml}$ in growth medium supplemented with $5 \%$ horse serum (Life Technologies). Beginning 24 hours after seeding, cultures were treated for 24 hours with $10 \mu M$ 5-azacytidine (Sigma). Cultures were then washed twice with HBSS, and the medium changed to growth medium containing 5\% horse serum, $50 \mu M$ hydrocortisone (Sigma), and $4 \mathrm{ng} / \mathrm{ml}$ basic fibroblast growth factor (Creative BioMolecules, Hopkinton, MA). The medium was changed twice a week for 3 weeks until the experiment was terminated. Controls for the myogenic treatment were cells cultured in growth medium supplemented with horse serum and vehicle solutions of the compounds of the myogenic medium. For a cell negative control, human dermal fibroblasts were kept under identical conditions. Experiments were carried out in triplicate.

To perform immunostaining for skeletal musclespecific myosin heavy chain (SkM-MHC), cells were rinsed twice with $\mathrm{PBS}$ and fixed with methanol at $-20^{\circ} \mathrm{C}$ for 30 minutes. Cells were incubated twice in $50 \mathrm{mM}$ ammonium chloride in PBS for 10 minutes to quench autofluorescence. Nonspecific antibody binding was blocked by incubating the cells in 5\% BSA in PBS for 1 hour. Cells were then incubated for 1 hour with a mouse anti-SkM-MHC monoclonal antibody (Zymed, South San Francisco, CA) diluted 1:5 in 0.5\% BSA in 
Table 1. Primers used for reverse transcription-polymerase chain reaction (PCR) analysis and expected sizes of PCR products*

\begin{tabular}{|c|c|c|c|}
\hline Gene & Sense primer & Antisense primer & Product, bp \\
\hline$\beta$-actin & 5'-TGACGGGGTCACCCACACTGTGCCCATCTA-3' & 5'-CTAGAAGCATTTGCGGTGGACGATGGAGGG-3' & 661 \\
\hline CD45 & 5'-AACCTGAAGTGATGATTGCTG-3' & 5'-TACCTCTTCTGTTTCCGCAC-3' & 500 \\
\hline $\mathrm{CD} 3 \delta$ & 5'-GTTTCTCTCTGGCCTGGTAC-3' & 5'-AGAAGACTCCCAAAGCAAGG-3' & 356 \\
\hline CD20 & 5'-TGTGACTGTGTGGTACCCTCTC-3' & 5'-CGTCTCTGTTTCTTCTTCTTCC-3' & 589 \\
\hline PECAM-1 & 5'-TCAAGAAAAGCAACACAGTCC-3' & 5'-ACTCCGATGATAACCACTGC-3' & 652 \\
\hline CD14 & 5'-CTGCGTGTGCTAGCGTACTC-3' & 5'-CGTCCAGTGTCAGGTTATCC-3' & 655 \\
\hline FLK-1 & 5'-TGTTGTTCTTTCCACCAGCAG-3' & 5'-ACGGTCTGGAAGGAACTCTC-3' & 646 \\
\hline Vimentin & 5'-AGATGCGTGAAATGGAAGAG-3' & 5'-AAATCTATCTTGCGCTCCTG-3' & 498 \\
\hline VCAM-1 & 5'-GACCTTCATCCCТАCCATTG-3' & 5'-ATACTCCCGCATCCTTCAAC-3' & 593 \\
\hline CD44 & 5'-TTGGAGATGGATTCGTGGTC-3' & 5'-GGACTCTTGGACTCTTCTGG-3' & 661 \\
\hline$\alpha \mathrm{v}$ integrin & 5'-AATGTGTAAAATCAGTCTCGGC-3' & 5'-ATACCTCAACTAAATGTGCTCC-3' & 483 \\
\hline$\alpha 1(\mathrm{I})$ collagen & 5'-CGTGGTGACAAGGGTGAGAC-3' & 5'-TAGGTGATGTTCTGGGAGGC-3' & 827 \\
\hline FGFR-1 & 5'-ACTCCACCGTCAGCTGTAAC-3' & 5'-CACTGACCTCCCTACTGCTG-3' & 419 \\
\hline Wnt5a & 5'-CСАССТТССТСТТСАСАCТG-3' & 5'-CGAACAAGTAATGCCCTCTC-3' & 770 \\
\hline GDF-5/CDMP-1 & 5'-GCCCTGTTCCTGGTGTTTGG-3' & 5'-GCTGTGTAGATGCTCCTGCC-3' & 595 \\
\hline$\alpha 1$ (II) collagen & 5'-CTGCTCGTCGCCGCTGTCCTT-3' & 5'-AAGGGTCCCAGGTTCTCCATC-3' & $\begin{array}{l}432(\mathrm{Col} 2 \mathrm{~A}) \\
225(\mathrm{Col} 2 \mathrm{~B})\end{array}$ \\
\hline$\alpha 1(\mathrm{IX})$ collagen & 5'-ACTGGGTTCTCTGGGTAGCC-3' & 5'-ATGTGCTGATCTGTCGGTGC-3' & 363 \\
\hline$\alpha 1(\mathrm{X})$ collagen & 5'-AATCCCTGGACCGGCTGGAATTC-3' & 5'-TTGATGCCTGGCTGTCCTGGAACC-3' & 267 \\
\hline LBK-AP & 5'-CTGGACCTCGTTGACACCTG-3' & $5^{\prime}$-GACATTCTCTCGTTCACCGC-3' & 546 \\
\hline Osteopontin & 5'-GCTAAACCCTGACCCATCTC-3' & 5'-ATAACTGTCCTTCCCACGGC-3' & 543 \\
\hline SkM-MHC & 5'-ATAGGAACACCCAAGCCATC-3' & 5'-TTTGCGTAGACCCTTGACAG-3' & 599 \\
\hline $\mathrm{aP} 2$ & 5'-TATGAAAGAAGTAGGAGTGGGC-3' & 5'-CCACCACCAGTTTATCATCCTC-3' & 290 \\
\hline PPAR $\gamma 2$ & 5'-AGGAGCAGAGCAAAGAGGTG-3' & 5'-AGGACTCAGGGTGGTTCAGC-3' & 474 \\
\hline
\end{tabular}

* PECAM-1 = platelet endothelial cell adhesion molecule 1; FLK-1 = fetal liver kinase 1; VCAM-1 = vascular cell adhesion molecule 1; FGFR-1 = fibroblast growth factor receptor 1; GDF-5/CDMP-1 = growth differentiation factor 5/cartilage-derived morphogenetic protein 1; Col2A = type IIA collagen; LBK-AP = liver-bone-kidney alkaline phosphatase; SkM-MHC = skeletal muscle-specific myosin heavy chain; aP2 = fatty acid-binding protein aP2; PPAR $\gamma 2=$ peroxisome proliferator-activated receptor $\gamma 2$. 
PBS. This antibody reacts with both human and mouse SkMMHC. Reactivity was detected with fluorescence microscopy after incubation for 1 hour with a Cy2-conjugated secondary antibody (goat anti-mouse IgG; Kirkegaard \& Perry) that had been diluted 1:200 in 0.5\% BSA in PBS. Nuclei were counterstained with 4',6-diamidino-2-phenylindole (ICN, AsseRelegem, Belgium). Green and blue images were superimposed using SPOT software (Diagnostic Instruments, Sterling Heights, MI). Negative controls were untreated cells incubated with primary antibody and treated cells incubated with normal mouse $\mathrm{IgG}$ instead of primary antibody. For a cell positive control, myotubes derived from $\mathrm{C} 2 \mathrm{C} 12$ mouse myoblasts were used.

In vitro adipogenesis. The in vitro adipogenesis assay was performed as described elsewhere (2). SM-derived cells were allowed to become confluent and were cultured for an additional 5 days. Adipogenic induction medium was then added, consisting of growth medium supplemented with $1 \mu M$ dexamethasone, $0.5 \mathrm{~m} M$ methyl-isobutylxanthine, $10 \mu \mathrm{g} / \mathrm{ml}$ insulin, and $100 \mathrm{~m} M$ indomethacin (all from Sigma). After 72 hours, the medium was changed to adipogenic maintenance medium $(10 \mu \mathrm{g} / \mathrm{ml}$ insulin in growth medium) for 24 hours. Cells were treated 4 times with adipogenic induction medium. The cultures were then maintained in adipogenic maintenance medium for 1 week before fixation. Controls for the adipogenic treatment were cells cultured in growth medium supplemented with vehicle solutions of the compounds of the adipogenic media. For a cell negative control, human dermal fibroblasts were kept under identical conditions. Experiments were performed in triplicate. After 3 weeks, cells were rinsed twice with PBS, fixed with $0.2 \%$ glutaraldehyde (Sigma) for 5 minutes, washed with distilled water, rinsed in $60 \%$ isopropanol, and covered with oil red O solution $(0.1 \%$ oil red O [Sigma] in $60 \%$ isopropanol). After 10 minutes, cultures were briefly rinsed in $60 \%$ isopropanol, washed thoroughly in distilled water, and counterstained with Carazzi's hematoxylin.

Total RNA extraction and semiquantitative reverse transcription (RT)-PCR analysis. Total RNA from synovial tissue and SM-derived cells was extracted using a commercially available kit (S.N.A.P.; Invitrogen, Groningen, The Netherlands), according to the manufacturer's instructions. Complementary DNA (cDNA) were obtained by RT of $1 \mu \mathrm{g}$ total RNA (Thermoscript; Life Technologies) with oligo(dT) ${ }_{20}$ as primer. PCR was performed in a volume of $10 \mu$ l. Complementary DNA were added to the following PCR mixture: 0.5 units Taq polymerase (Eurogentec, Seraing, Belgium), $0.2 \mathrm{mM}$ dNTP, $0.5 \mu M$ specific primers, and $1.5 \mathrm{~m} M \mathrm{MgCl}_{2}$. Negative controls were either RT without enzyme or PCR with Milli-Q (Millipore, Brussels, Belgium) ultrapure water instead of cDNA. PCR reactions were carried out in a Perkin Elmer Thermal Cycler 9600 . After denaturation at $95^{\circ} \mathrm{C}$ for 1 minute, cycles were 10 seconds at $94^{\circ} \mathrm{C}, 10$ seconds at the optimal annealing temperature, and 30 seconds at $72^{\circ} \mathrm{C}$. Cycling was followed by 10 -minute elongation at $72^{\circ} \mathrm{C}$.

Primer pairs were designed using Vector NTI software (InforMax, North Bethesda, MD). The sequences of the primers and the sizes of the PCR products are shown in Table 1. Before marker analysis, cDNA were equalized for the expression of the housekeeping gene $\beta$-actin. PCR products were electrophoresed in $1.5 \%$ agarose gel in Tris-borateEDTA electrophoresis buffer, stained with ethidium bromide, visualized by ultraviolet transillumination, and analyzed by densitometry using the Image Master software (Amersham Pharmacia Biotech, Roosendaal, The Netherlands).

\section{RESULTS}

In vitro expandability, with limited senescence, of SM-derived cells. SM-derived cell cultures were initiated as primary cultures of cells that grew out of SM-derived cell suspensions by selectively attaching to tissue culture plastic. After the first passage and throughout in vitro expansion, SM-derived cells appeared microscopically to be a relatively homogeneous population of fibroblast-like cells.

Stem cells display a long-term self-renewal capacity. We investigated the in vitro expandability of SMderived cells from donors of various ages. Starting from the first passage, we analyzed the kinetics of growth of SM-derived cells from all donors tested. Figure 1A shows that although no significant telomerase activity was detected, the growth curve of SM-derived cells from 2 donors was linear up to 30 population doublings (Figure 1B). In all donors tested, SM-derived cells were expanded over at least 10 passages, with a similar kinetics of growth (data not shown).

Cell senescence, a common phenomenon occurring to various degrees in many somatic cells during in vitro culture expansion, is known to induce phenotypic and functional changes (21). Therefore, we analyzed SA- $\beta$-gal activity in SM-derived cells from all donors during expansion. At early passages (before P6), <1\% of the cells displayed detectable SA- $\beta$-gal activity. Weakto-moderate $\beta$-gal staining of a few scattered cells (10-20\%) was observed at late passages (after P10) (Figure 1C). To test whether cryopreservation could affect cell senescence, SA- $\beta$-gal activity of SM-derived cells that had been cryopreserved was compared with that of passage-matched cells that had never been frozen. No apparent differences were detected between cryopreserved and noncryopreserved cells (not shown).

Characterization of the SM-derived cells during the in vitro isolation and expansion procedure. To evaluate possible contamination by cells belonging to the hematopoietic and/or endothelial lineages and to characterize in vitro-expanded SM-derived cells, RT-PCR gene expression analysis was performed on samples at different steps of the isolation and expansion procedure. We compared the expression of several marker genes by SM as a tissue, by isolated cells immediately after 

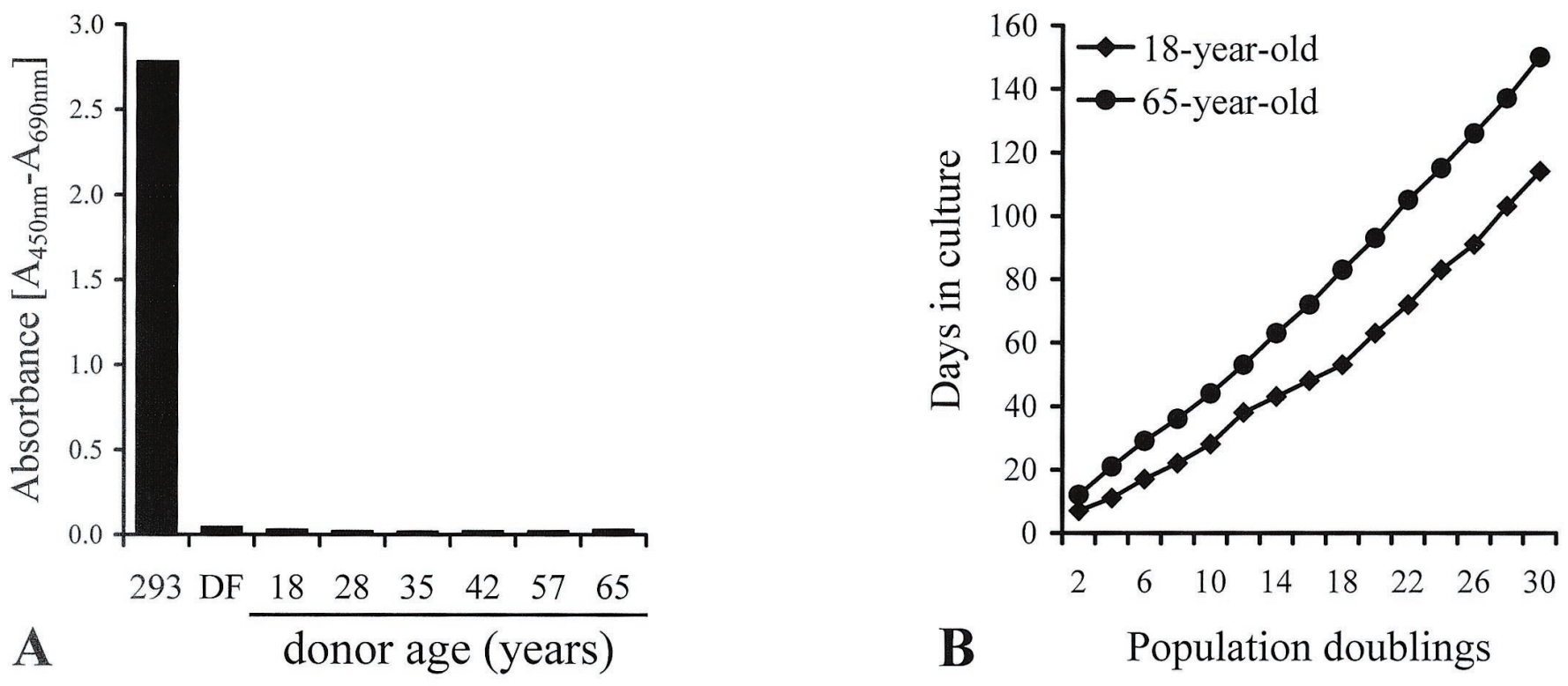

C
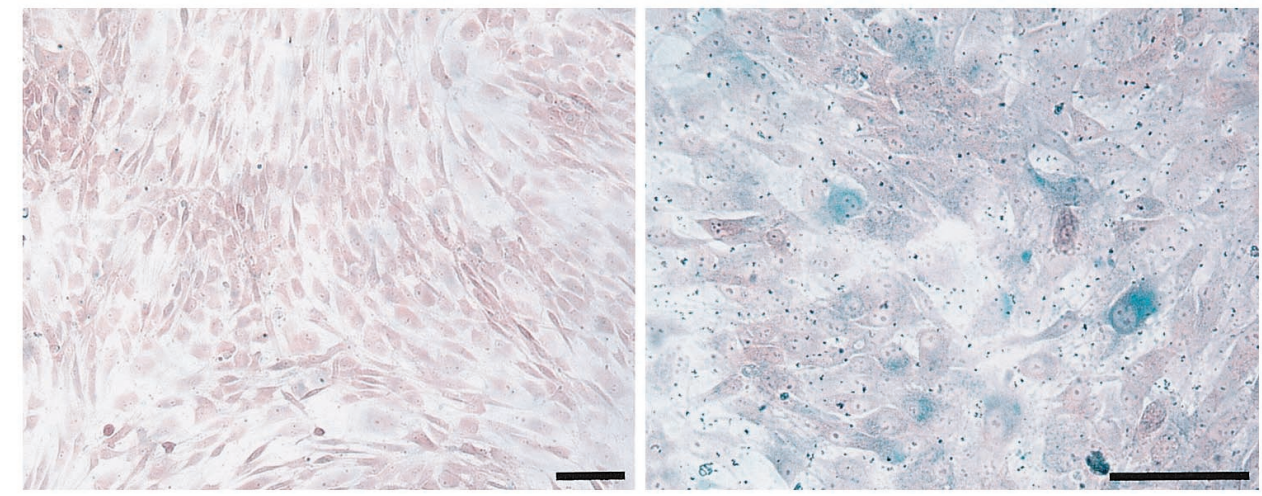

P12

Figure 1. Extensive in vitro expandability, with limited senescence, of synovial membrane (SM)-derived cells. A, Telomerase activity in passage 3 (P3) SM-derived cells from donors of various ages. Human embryonic kidney 293 cells (293) and P3 human dermal fibroblasts (DF) are positive and negative controls, respectively. B, Kinetics of growth of SM-derived cells from 2 donors of different ages. The kinetics of growth were analyzed starting from the first passage. Cells were expanded in monolayer with serial 1:4 dilution passages every time they reached confluence. Although no significant telomerase activity was detected, the growth curve was linear up to 30 population doublings. C, Senescence-associated $\beta$-galactosidase staining. SM-derived cells at P3 and P12 from a 65-year-old donor are shown. Counterstaining is with neutral red. SM-derived cells can be expanded for many passages with no significant senescence $(<1 \%$ of the cells). Few positive SM-derived cells $(\sim 10-20 \%)$ are visible at late passages $($ after P10). Bars $=50 \mu \mathrm{m}$.

overnight collagenase digestion, by adherent confluent primary SM-derived cells (P0), and by cells at P3 and P10. P0 cells were analyzed because they were used for the cell cloning, while P3 and P10 cells were included because all the in vitro experiments for multilineage potential were carried out within this range of passages. During this time, SM-derived cells constituted a homogeneous-appearing cell population (ref. 22 and the present study). The gene expression analysis included hematopoietic and endothelial markers, as well as genes previously reported to be expressed by synovial tissue (23) or synovial cells in vitro (22). In addition, we screened for a number of genes known to have a role in skeletal development and maintenance (24).

The genes analyzed are listed in Table 2. Figure 2 shows a representative panel of the genes tested. During the cell isolation procedure and subsequent expansion in monolayer, a rapid disappearance of hematopoietic and 
endothelial markers occurred. The monocyte marker CD14 (25) and the endothelial marker fetal liver kinase 1 (26) were barely detectable in P0 SM-derived cells,

Table 2. Molecular characterization of adult human synovial membrane-derived mesenchymal stem cells, as determined by reverse transcription-polymerase chain reaction*

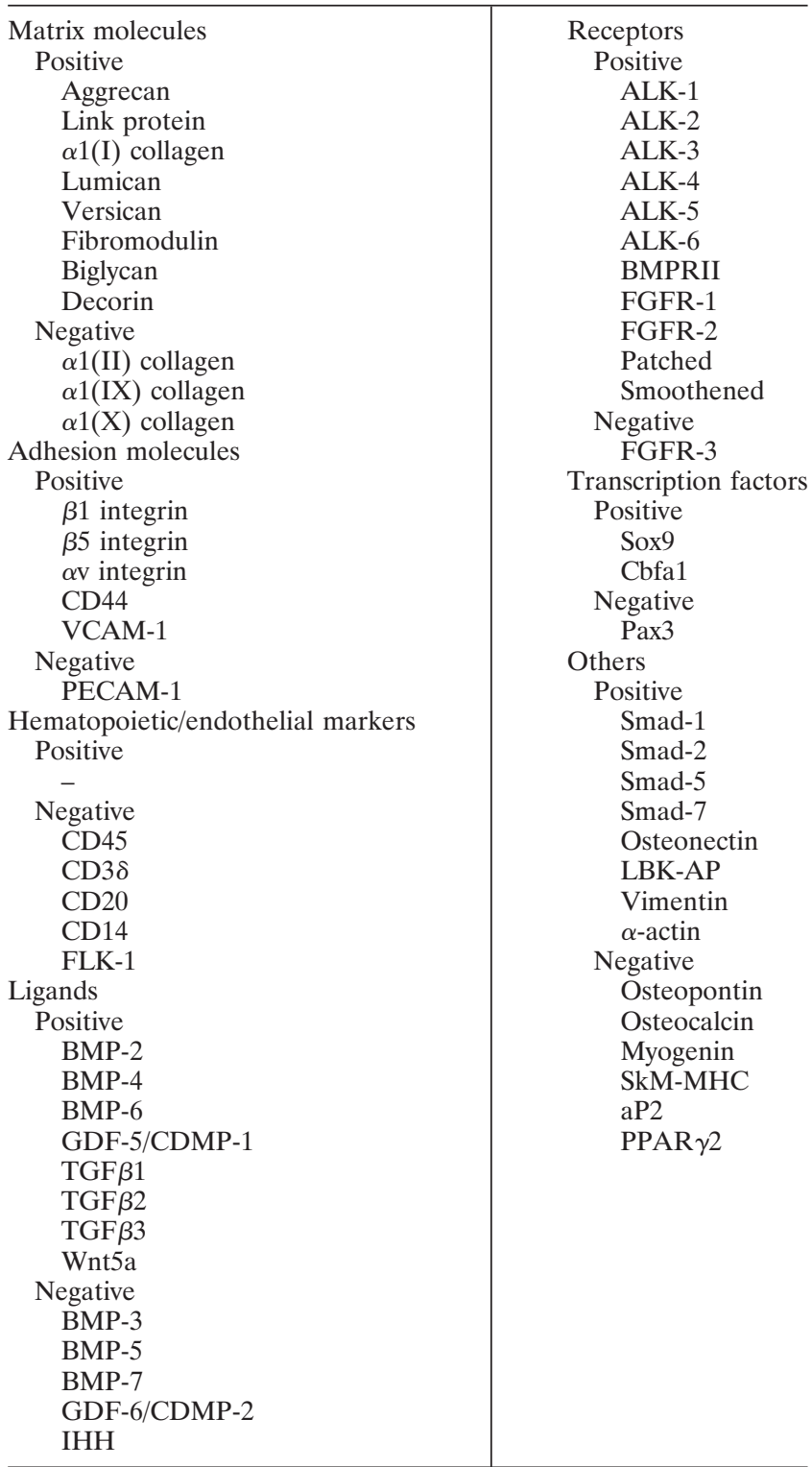

* The analysis included expanded cells between passage 3 (P3) and P10. Positive or negative $=$ presence or absence, respectively, of the given matrix or adhesion molecule, hematopoietic/endothelial marker, ligand, receptor, or transcription factor between $\mathrm{P} 3$ and $\mathrm{P} 10$; BMP = bone morphogenetic protein; TGF $\beta=$ transforming growth factor $\beta$; $\mathrm{IHH}=$ Indian hedgehog; ALK $=$ activin receptor-like kinase; BMPRII $=$ BMP receptor type II (see Table 1 for other definitions).

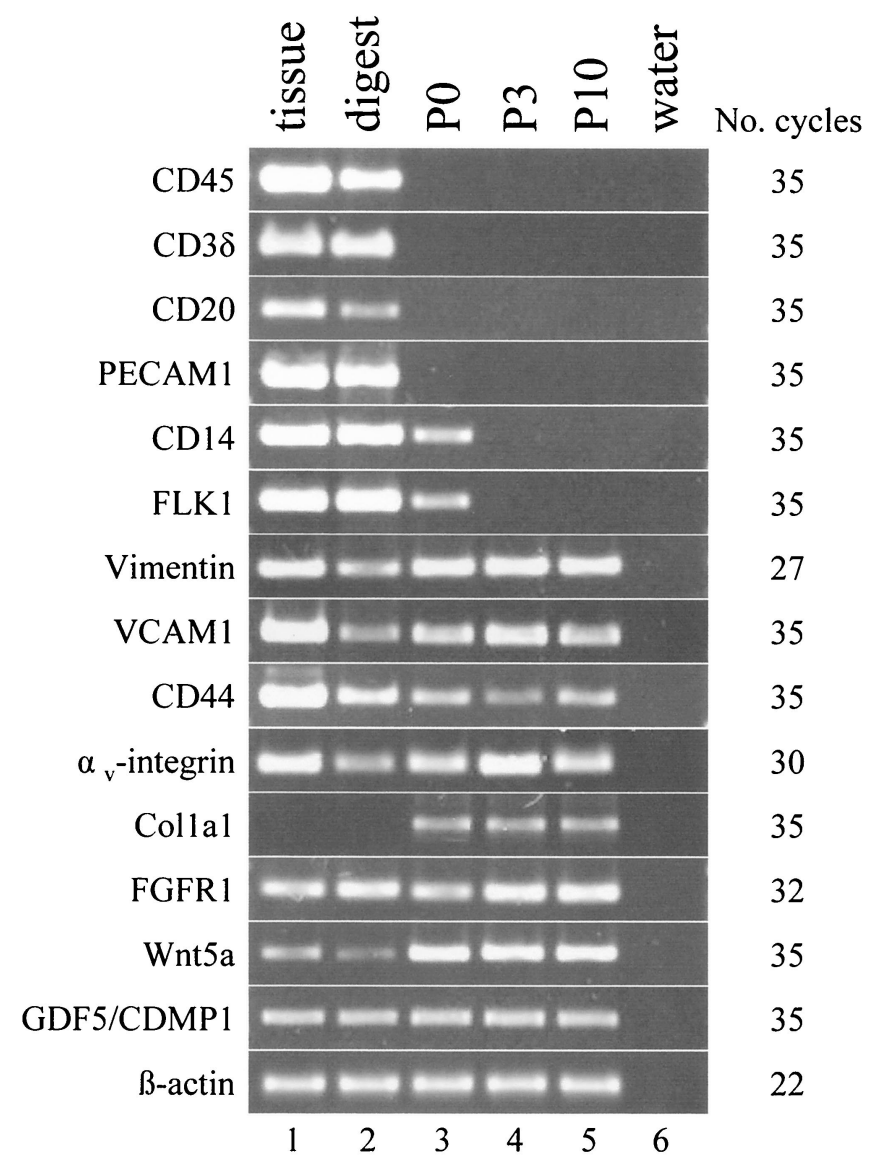

Figure 2. Characterization of the SM-derived cells during the in vitro isolation and expansion procedure. Semiquantitative reverse transcription-polymerase chain reaction (PCR) analysis was performed for the expression of a large number of genes (see text for details). Shown is a representative panel of the genes tested. During the cell isolation procedure and subsequent expansion in monolayer, the hematopoietic and endothelial markers tested rapidly disappear, becoming undetectable after P3. Between P3 and P10, the molecular profile of the SM-derived cells remains stable. Complementary DNA are equalized for $\beta$-actin expression. Lane 1, Synovial tissue; lane 2, cells after overnight collagenase digestion; lanes 3-5, confluent monolayer cells at different passages ( $\mathrm{P} 0, \mathrm{P} 3$, and $\mathrm{P} 10)$; lane 6, Milli-Q water negative control. The numbers of PCR cycles are shown. PECAM1 = platelet endothelial cell adhesion molecule 1 ; FLK1 = fetal liver kinase 1; VCAM1 = vascular cell adhesion molecule 1; Col1a1 $=\alpha 1(\mathrm{I})$ collagen; FGFR1 = fibroblast growth factor receptor 1; GDF5/ CDMP1 $=$ growth differentiation factor $5 /$ cartilage-derived morphogenetic protein 1 . See Figure 1 for other definitions.

while they could not be detected in P3 and P10 cells even after 35 PCR cycles (Figure 2).

The molecular profile of the SM-derived cells was stable during expansion from P3 up to at least P10 

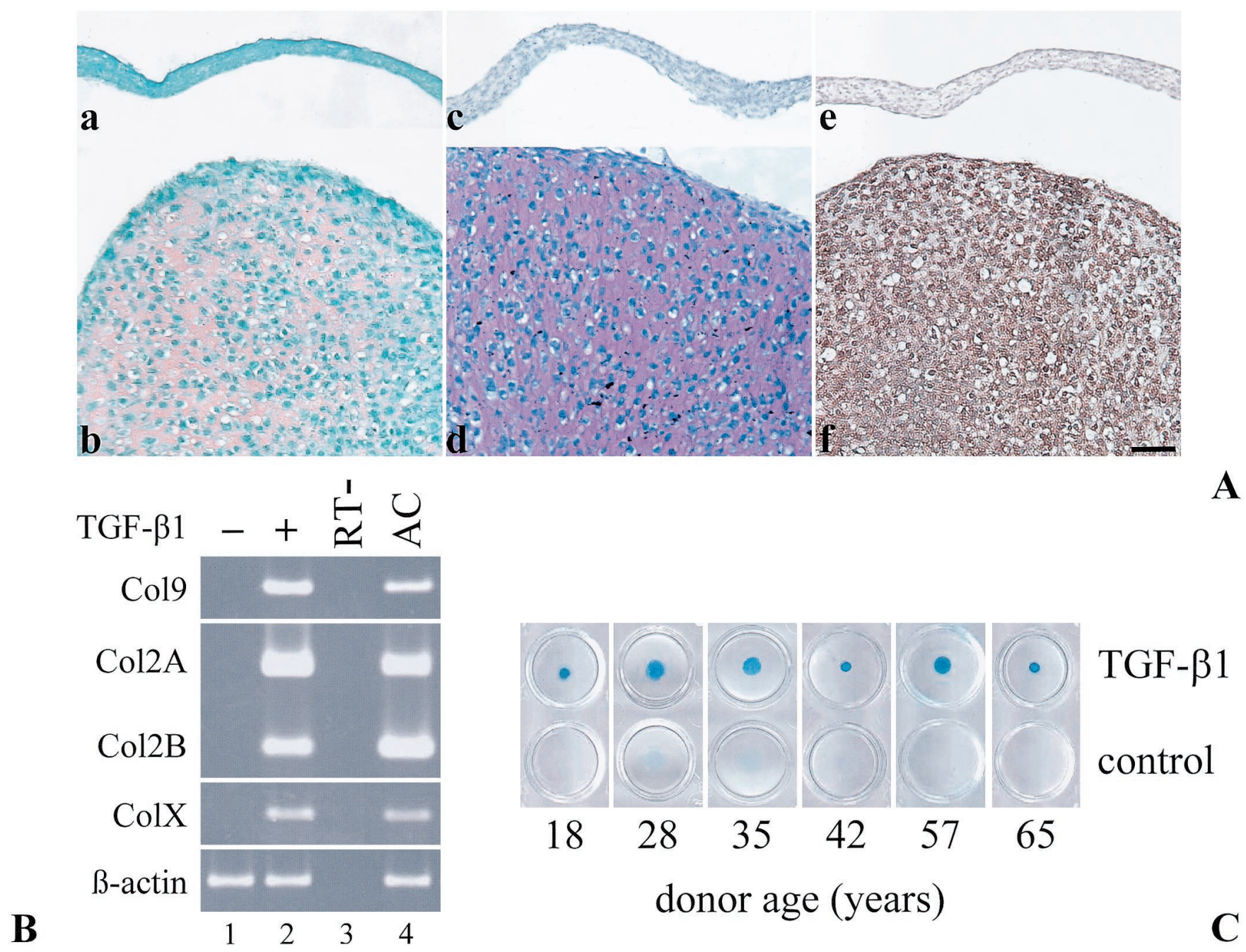

Figure 3. Chondrogenic differentiation of SM-derived cells. A, Safranin O (a and b) and toluidine blue (c and d) stainings of paraffin sections of micromasses either treated (b and d) or not treated (a and $\mathbf{c}$ ) with $10 \mathrm{ng} / \mathrm{ml}$ transforming growth factor $\beta 1$ (TGF- $\beta 1$ ) for 3 weeks. e and f, Immunohistochemical analysis of paraffin sections with anti-type II collagen antibody. e, Untreated micromass. f, Micromass treated with TGF- $\beta 1$ for 3 weeks. Nuclei were counterstained with hematoxylin. Findings indicate the presence of cartilage differentiation in the micromasses treated with TGF- $\beta 1$. Bar $=50 \mu \mathrm{m}$. B, Semiquantitative reverse transcription (RT)-PCR analysis for cartilage markers. SM-derived cells were subjected to the chondrogenesis assay. The levels of collagen types IX (Col9), IIA (Col2A), IIB (Col2B), and X (ColX) mRNA expressed by SM-derived cells in micromass culture treated for 3 weeks with TGF- $\beta 1$ (lane 2) were comparable with those expressed by freshly isolated normal human articular chondrocytes (AC) (lane 4). Untreated SM-derived cells were negative (lane 1). Lane 3, RT negative control. Complementary DNA were equalized for $\beta$-actin expression. $\mathbf{C}$, Chondrogenesis was obtained in all TGF- $\beta 1$-treated donor samples tested. After expansion in monolayer, SM-derived cells from all donors were plated in micromass culture and were either treated or not treated with TGF- $\beta 1$. After 6 days, micromasses were fixed and stained with Alcian blue. For each donor, the experiment was performed in triplicate. Controls were untreated SM-derived cells in micromass culture in the presence of the carrier solution used for TGF- $\beta 1$. See Figures 1 and 2 for other definitions.

(Figure 2) and was independent of the age of the donors (data not shown). To test whether cryopreservation could affect the phenotype of SM-derived cells, cells that had been cryopreserved were compared with passagematched cells that had never been frozen for their expression of the same panel of markers. No phenotypic differences were detected between cryopreserved and noncryopreserved cells (data not shown).

Chondrogenesis. TGF $\beta 1$-treated micromasses displayed cartilage-specific metachromasia with toluidine blue and Safranin O staining. Safranin O staining is specific for highly sulfated proteoglycans, a unique bio- 


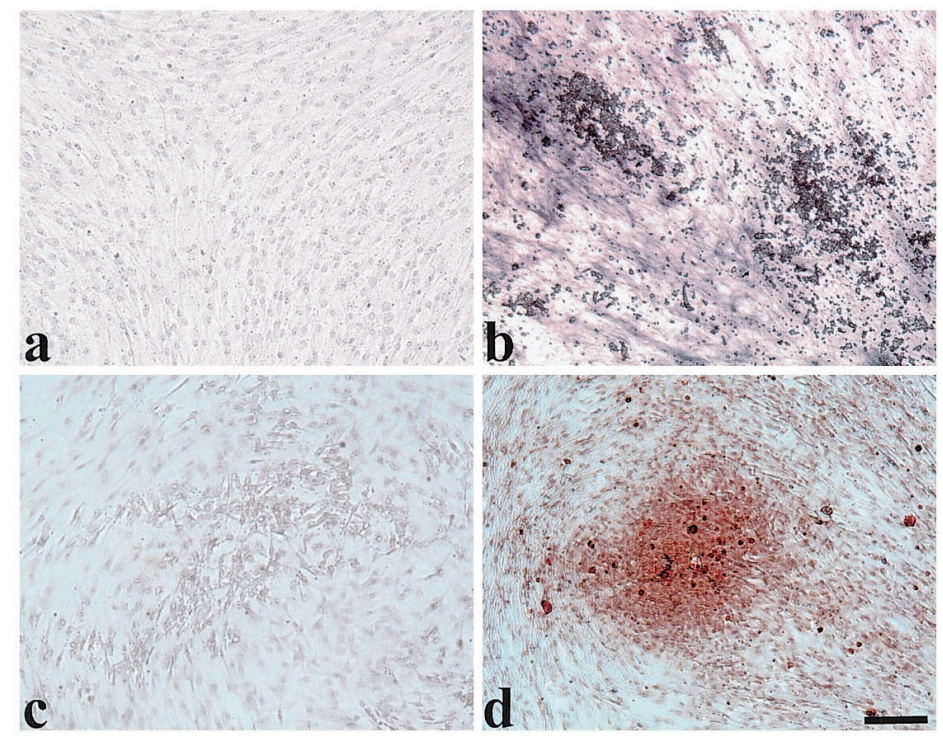

A

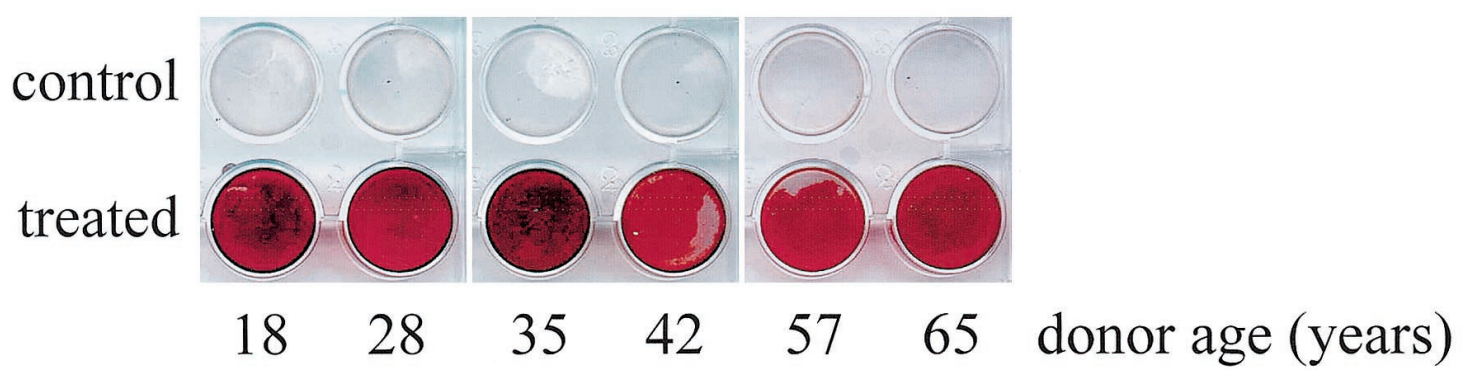

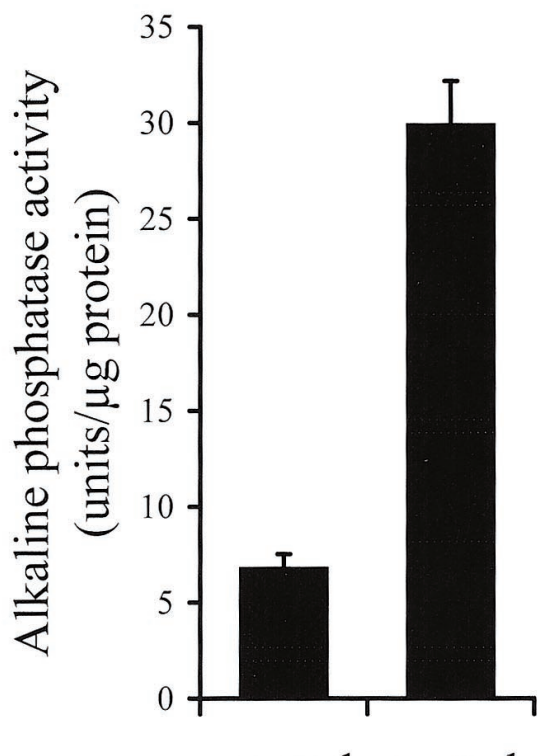

control treated
C

Figure 4. Osteogenic differentiation of synovial membrane (SM)-derived cells. A, Monolayer SM-derived cells were either treated (b and d) or not treated (a and $\mathbf{c}$ ) with osteogenic medium. After 2 weeks, cells were fixed and stained for alkaline phosphatase (a and $\mathbf{b})$ or with alizarin red for calcium deposits (c and d). In a and b, nuclei were counterstained with hematoxylin. Bar $=50 \mu \mathrm{m}$. B, Alkaline phosphatase activity. After a 2-week treatment, alkaline phosphatase activity was determined and expressed as arbitrary units per microgram of protein content. Data were expressed as the mean and SD of 4 wells. C, Osteogenesis was obtained in all osteogenic medium-treated donor samples tested. SM-derived cells from all donors were either treated or not treated with osteogenic medium. After 4 weeks, cultures were fixed and stained with alizarin red. For each donor, the experiment was performed in triplicate. Controls for the osteogenic treatment were SM-derived cells cultured in growth medium supplemented with vehicle solutions of the compounds of the osteogenic medium.

chemical feature of cartilage proteoglycans (27). The detection of type II collagen protein by immunostaining and of collagen types IIA, IIB, IX, and X messenger RNA (mRNA) by semiquantitative RT-PCR further confirmed the cartilage phenotype of the tissue generated in vitro. Untreated micromasses were negative (Figures $3 \mathrm{~A}$ and $\mathrm{B}$ ). Chondrogenesis, as evaluated by Alcian blue staining, was obtained in all TGF $\beta 1$-treated donor samples tested (Figure 3C).

Osteogenesis. SM-derived cells treated with osteogenic medium underwent a change in their morphology from spindle shaped to cuboidal, and formed large nodules that stained for alkaline phosphatase and with alizarin red (Figure 4A). This process was associated with a significant increase in alkaline phosphatase activity (Figure 4B). Calcium deposits, detected by alizarin red staining, were evident after $\sim 10$ days and increased over time. Osteogenic differentiation, as determined by alizarin red staining, was achieved in all osteogenic medium-treated donor samples tested (Figure 4C).

Myogenesis. Myogenesis was demonstrated by the induction of SkM-MHC mRNA, as determined by RT-PCR, in SM-derived cells cultured under myogenic conditions (Figure 5A). In addition, long multinucleated 

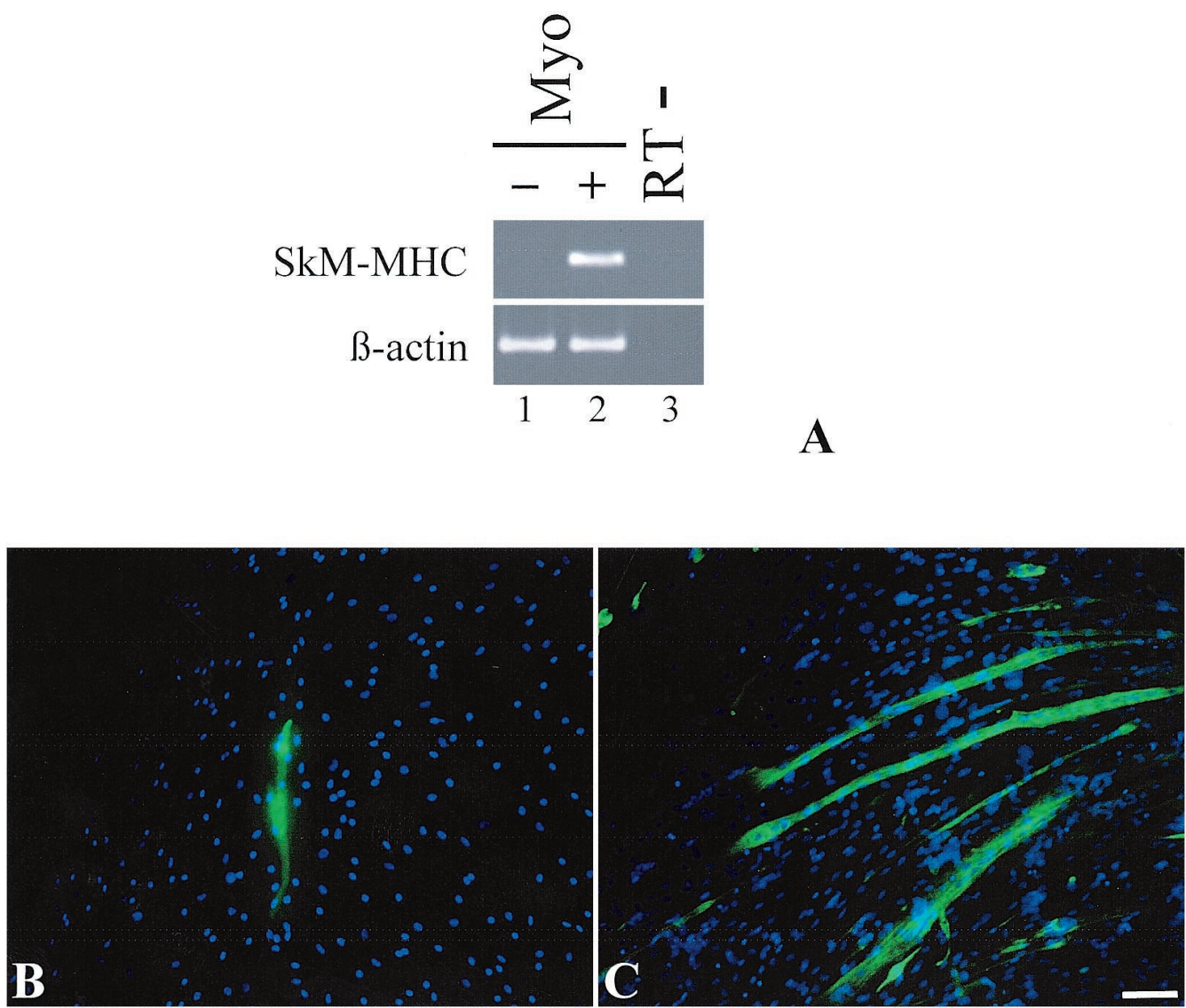

Figure 5. Myogenic differentiation of SM-derived cells. A, Semiquantitative RT-PCR analysis for skeletal muscle-specific myosin heavy chain (SkM-MHC). SM-derived cells were subjected to the myogenesis assay. SkM-MHC mRNA was induced in treated cells (+Myo; lane 2), while untreated cells were negative ( - Myo; lane 1). Lane 3, RT negative control. Complementary DNA were equalized for $\beta$-actin expression. B and $\mathbf{C}$, Immunostaining for SkM-MHC in SM-derived cells and $\mathrm{C} 2 \mathrm{C} 12$ cells, respectively. Myotubes obtained from SM-derived cells were smaller and less uniform in shape than those obtained from $\mathrm{C} 2 \mathrm{C} 12$ cells. Bar $=50 \mu \mathrm{m}$. See Figures 1-3 for other definitions.

cells, reminiscent of myotubes, which stained positively with the antibody to SkM-MHC, were detected in all treated samples (Figures 5B and C). They were isolated and scattered, with a frequency of $\sim 1 / 10^{5}$. Their number remained stable over a period of 3 weeks. Untreated cells did not form myotubes and were negative for SkM-MHC (Figure 5A). Neither the myotubes obtained from SM-derived cells nor those from $\mathrm{C} 2 \mathrm{C} 12$ cells exhibited discernible striations under the conditions employed in this study.

Adipogenesis. Adipogenic differentiation was demonstrated by the accumulation of lipid vacuoles and by the expression of adipose-specific genes. In all samples, lipid vacuoles were already observed after the first induction treatment and increased over time in both size and number until they underwent coalescence. Such lipid vesicles stained with oil red $\mathrm{O}$, while untreated cultures were negative (Figure 6). Four induction treatments resulted in $\sim 30-80 \%$ of the cells committing to this lineage, depending on the sample. No apparent correlation was observed with donor age or cell passage number.

Treatment-induced in vitro differentiation is a lineage-specific event. To investigate whether differentiation to a certain lineage was specific to each treatment, cultures from each treatment were cross-stained with oil red $\mathrm{O}$, Alcian blue, or alizarin red, or were immunostained for SkM-MHC. Stainings were preceded by the appropriate fixation procedures. Cultures were positive only with the staining specific to the desired 


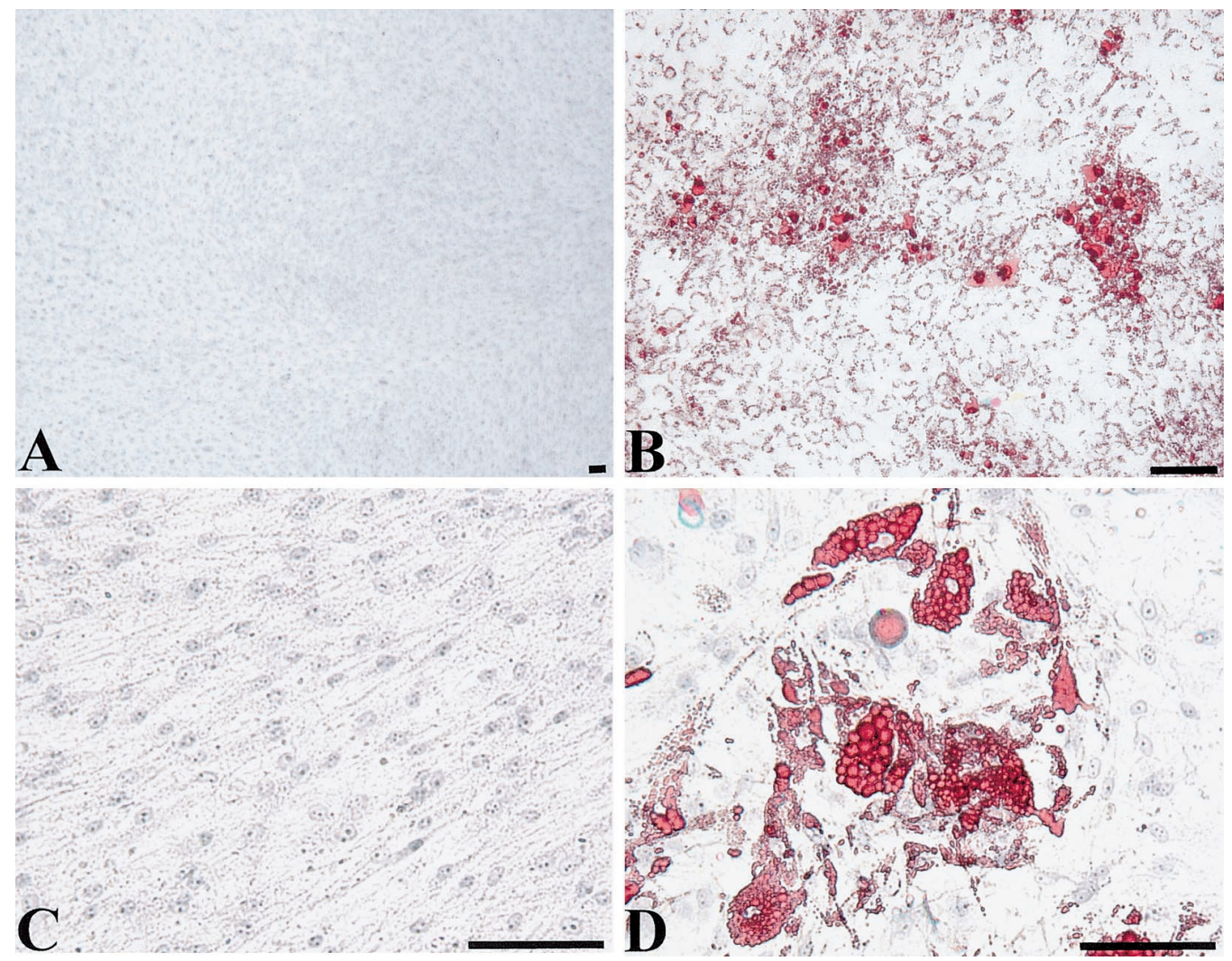

Figure 6. Adipogenic differentiation of synovial membrane-derived cells. Oil red $\mathrm{O}$ staining of cultures that were either $\mathbf{B}$ and $\mathbf{D}$, treated or $\mathbf{A}$ and $\mathbf{C}$, not treated with adipogenic media for 3 weeks. D, Morphologic details of a treated culture. C, Parallel control. Nuclei were counterstained with hematoxylin. Bars $=50 \mu \mathrm{m}$.

lineage, while the other stainings were all negative (not shown), indicating that differentiation was specific to the treatment.

To further test the possibility that a small cell subpopulation could differentiate to lineages other than those desired in the in vitro assays, after 3-week treatments, cultures were subjected to semiquantitative RTPCR analysis for the expression of selected marker genes of the lineages examined. RT-PCR is known to be highly sensitive for gene expression detection. Neither the adipogenic, the osteogenic, nor the myogenic cultures contained cells of multiple lineages. The chondrogenic cultures expressed osteopontin, which was also detected at comparable levels in normal articular chondrocytes, and displayed a slight increase in alkaline phosphatase. The osteogenic cultures showed strong up-regulation of osteopontin and alkaline phosphatase (Figure 7).
Multilineage potential of SM-derived cells is independent of cell passage number, donor age, or cryopreservation, and is conserved in clonal cells. At different passages (from P3 up to P10), we tested SM-derived cells from adult donors of various ages under conditions favorable for chondrogenic, osteogenic, myogenic, or adipogenic differentiation in vitro. Cells differentiated into the specific phenotype induced, regardless of cell passage number or donor age, within the ranges examined (not shown). Importantly, no apparent impairment of the multilineage potential of SMderived cells was evident after cryopreservation (data not shown). In contrast, under the same culture conditions, normal dermal fibroblasts, which are cells of mesenchymal lineage, failed to undergo any such differentiation (data not shown).

We wished to determine whether individual SMderived cell clones could differentiate to all lineages, or 


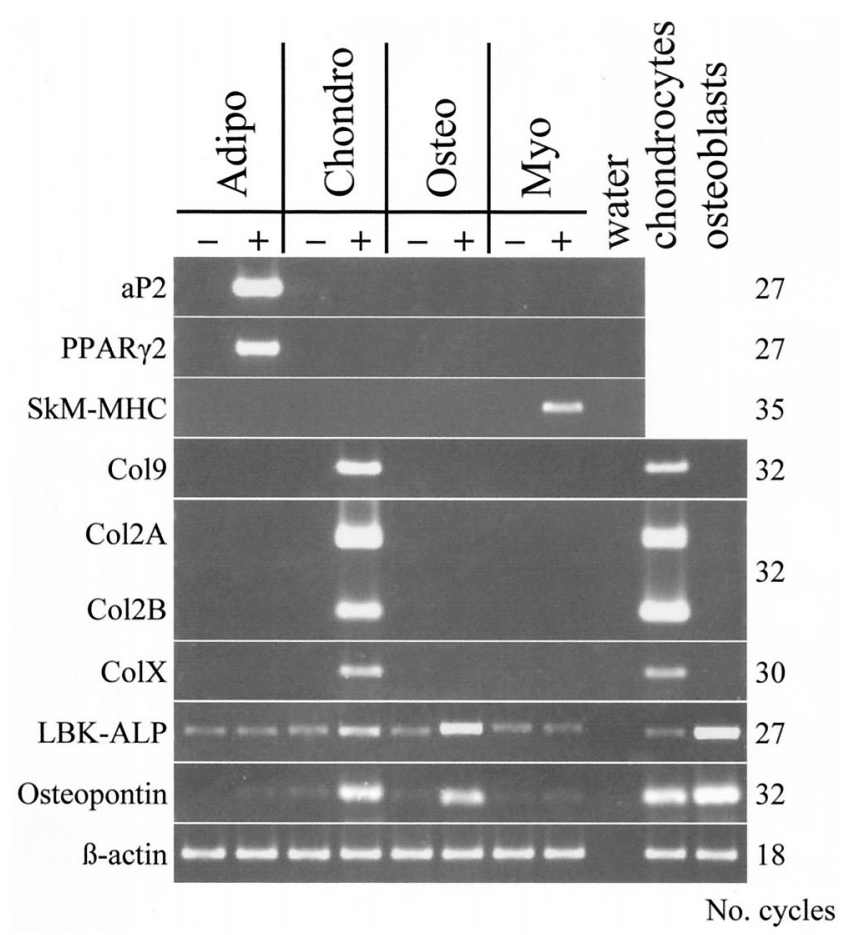

Figure 7. Differentiation in vitro is restricted to the directed lineage, as shown by reverse transcription-polymerase chain reaction (RTPCR). Cultures of synovial membrane-derived cells treated in each differentiation condition (+Adipo, +Chondro, +Osteo, +Myo) for 3 weeks, as well as parallel controls, were subjected to semiquantitative RT-PCR to analyze the expression of lineage-related marker genes and to reveal whether any cells differentiated to lineages other than the one related to the treatment. Freshly isolated human articular chondrocytes and human trabecular osteoblasts were used as positive controls for chondrogenic and osteogenic markers, respectively. Complementary DNA were equalized for $\beta$-actin expression. The numbers of PCR cycles are shown. aP2 = fatty acid-binding protein $\mathrm{aP} 2$; PPAR $\gamma 2=$ peroxisome proliferator-activated receptor $\gamma 2$; LBKALP $=$ liver-bone-kidney alkaline phosphatase. See Figures 3 and 5 for other definitions.

whether cell precursors specific to each lineage were present. SM-derived cells were subjected to classical limiting dilution, yielding 8 independent clones. Three clones stopped growing very early, either in the 96-well tissue culture plate or when transferred to a 24-well tissue culture plate. In these 3 cell clones, SA- $\beta$-gal staining was strongly positive (data not shown). The remaining 5 clones could be sufficiently expanded to perform the in vitro differentiation assays. As shown in Table 3, upon treatment, all clones underwent chondrogenic, osteogenic, and adipogenic differentiation. Myogenic differentiation was obtained in only 1 clone. A few scattered, rudimentary myotubes were observed, with a frequency similar to that reported in parental cells. Such myotubes stained positively with the antibody to SkMMHC.

\section{DISCUSSION}

MSCs are defined as highly clonogenic cells capable of both self renewal and multilineage differentiation (2). In the present study, we characterized a population of MSCs derived from adult human SM. These cells possessed high self-renewal capacity over at least 10 passages, with limited senescence. We demonstrated that expanded SM-derived cells under appropriate culture conditions can be induced to differentiate in vitro toward chondrogenesis, osteogenesis, myogenesis, and adipogenesis, independently of donor age, within the ranges examined. We proved that the multilineage differentiation potential is inherent in individual cell clones.

The self-renewal capacity of SM-derived MSCs is remarkable. The activity of telomerase, a ribonucleoprotein polymerase that regulates cell proliferative life span (28), was not detected under our experimental conditions. These data are in keeping with reports in the literature $(29,30)$. Telomere elongation by telomerase is thought to be necessary to guarantee a high number of cell divisions (28). Despite the lack of detectable telomerase activity, SM-derived MSCs maintained a linear growth curve over at least 30 population doublings. This high self-renewal capacity might be attributable to the length of telomeres in the original cell population within the synovial tissue, which would counterbalance the undetectable telomerase activity (31). Telomeraseindependent mechanisms to preserve the telomere length have also been postulated (28). Alternatively, a small subpopulation of cells possessing significant telomerase activity could be responsible for this self-renewal

Table 3. Differentiation potential of synovial membrane-derived cell clones*

\begin{tabular}{ccccc}
\hline \multicolumn{5}{c}{ Phenotype } \\
\cline { 2 - 5 } Clone & Chondrogenic & Osteogenic & Myogenic & Adipogenic \\
\hline 1 & + & + & - & + \\
2 & + & + & + & + \\
3 & + & + & - & + \\
4 & + & + & - & + \\
5 & + & + & - & + \\
\hline
\end{tabular}

* The differentiation potential of synovial membrane-derived clonal cells was assessed as indicated in Materials and Methods. All clones displayed the potential to differentiate toward the chondrogenic, osteogenic, and adipogenic lineages, as revealed by histochemical stainings. Myogenesis was observed in only 1 clone. 
capacity. Scattered phenomena of cell senescence, known to be related to telomere shortening (28), were observed in late passage (after P10) SM-derived cells. Taking into consideration the high number of cells already obtainable after a few passages (about 1 billion cells after 6 passages, starting with 10-50 mg synovial tissue from the knee joint), senescence may not represent a significant factor limiting cell expansion.

The chondrogenic potential of synovium and early-passage SM-derived cells has been previously described in rabbits $(32,33)$. In the present study, we confirm that chondroprogenitor cells are also present in the adult human SM. Importantly, the chondrogenic potential of these cells seems to be independent of donor age, retained throughout expansion over at least 10 passages and after cryopreservation. An age-related decrease in the chondrogenic differentiation potential has been reported in rabbit periosteum (34) and synovium (33) in an ex vivo organ culture (12). In our study, the absence of a significant decline in chondrogenic potential of SM-derived cells from older donors may be due to enrichment in progenitor cells by the cell isolation technique. The subsequent expansion of this selected cell subpopulation would most probably equalize the possible differences in the numbers of progenitor cells present in the original tissue samples.

Progenitor cells present in the SM could be responsible for the cartilaginous metaplasia observed in synovial chondromatosis, characterized by the formation of cartilage nodules within the SM $(35,36)$. Although TGF $\beta 1$ has been detected in synovial chondromatosis (37), its role in the pathogenesis of this process remains unclear.

Multiple injections of TGF $\beta 1$ into murine knee joints cause the formation of osteophytes, which have been interpreted as being of periosteal origin (38-40). The chondro-osteogenic potential of periosteum is known (11-13). However, progenitor cells present in the SM might contribute to the process of osteophyte formation observed in TGF $\beta 1$-injected joints.

SM-derived MSCs have the capacity to differentiate in vitro into the myogenic phenotype. Marrowderived MSCs have been reported to form groupings of large myotubes (20). In the present study, SM-derived cells formed sporadic atypical myotubes that stained positively for SkM-MHC. The observation that, under our experimental conditions, myogenesis occurred in a very limited number of SM-derived cells could be explained by factors related to the culture conditions. Alternatively, it would indicate the existence of a subpopulation of cells with broader differentiation poten- tial. The finding that myotubes formed in 1 of the 5 independent cell clones tested would corroborate this hypothesis. In the clone with myogenic potential, however, the number of myotubes observed was very limited. A possible explanation is that during expansion, cells would undergo a "desynchronization" process of their spontaneous differentiation stages. Hence, at the time of treatment, a subpopulation of cells would be more competent to a certain signal for a specific lineage than other cell subpopulations. The focal distribution of the adipogenic differentiation observed in both parental and clonal cells would lend support to this interpretation. However, the clonal cell isolation and extensive expansion may have caused some loss of multilineage potential that was originally present in these cells, as has been suggested for bone marrow-derived MSCs (41).

To respond to inductive signals, competent cells must be surrounded by similar cells (42). This phenomenon, the "community effect," has been described in the mammalian embryo as a prerequisite for mesodermal cells to undergo differentiation into skeletal muscle (43). The failure by SM-derived cells to achieve, under our experimental conditions, the minimal size of such a "community" necessary to permit myogenic differentiation would explain, at least in part, the formation of rudimentary myotubes.

The presence of foci of differentiation, especially in myogenic and adipogenic cultures, suggests that differentiation is not achieved uniformly by all cells. There is indeed the possibility that only a subpopulation of cells undertakes differentiation. In the absence of MSCspecific markers, we can only argue that cells not recruited into the specific lineage program were retaining the undifferentiated multipotent phenotype.

The multilineage potential of SM-derived MSCs can be explained either by the presence of multipotent individual cells or by the coexistence of distinct cell precursors specific for each mesenchymal lineage. Our cell cloning data support the former hypothesis. The prevalence of multipotent clones is not representative of the original number of progenitor cells in the synovial tissue. Instead, it is the result of a selection and subsequent enrichment of MSCs during the in vitro manipulations. Our data suggest that a small population of multipotent, highly clonogenic cells in the native synovial tissue is selected and eventually prevails throughout the isolation procedure and subsequent expansion in vitro. Indeed, most hematopoietic markers disappear during cell release and attachment. A further enrichment appears to occur throughout in vitro expansion, probably due to MSCs overgrowing other cell types. 
However, we cannot exclude the possibility that the disappearance of hematopoietic and endothelial markers is due to phenotypic rearrangements.

Three cell clones underwent growth arrest and therefore could not be characterized. They were senescent, as determined by SA- $\beta$-gal staining. At P0, when the cell cloning was performed, hematopoietic/ endothelial markers were still detectable. Therefore, the 3 cell clones either were contaminating non-MSCs or were senescent MSCs.

Therapeutic use of progenitor cells involves the potential risk of unintended differentiation and formation of tissues inappropriate for the specific application (44). To test the possibility that a small cell subpopulation could differentiate to lineages other than those desired in the in vitro assays, all cultures were subjected to semiquantitative RT-PCR analysis for the expression of selected marker genes of the lineages examined. RT-PCR is known to be a sensitive assay for gene expression detection. The differentiation was found to be restricted to the lineage specific to the treatment, with no apparent contamination by the other lineages examined. The detection of osteopontin in chondrogenic cultures is not at odds with this finding, since osteopontin is also expressed at comparable levels by normal human articular chondrocytes, as evaluated by RT-PCR. The slight up-regulation of alkaline phosphatase in chondrogenic cultures is most likely due to some degree of hypertrophy, as documented by the appearance of type X collagen (Figure 7).

In the absence of a marker specific to MSCs, it is currently not possible to address the topographic distribution of these cells inside the synovial tissue. Therefore, we can only speculate about the origin of SMderived MSCs. They might be derived from precursor cells that enter the joint from the circulation. The identification of stem cells in the blood would support this hypothesis (45). Alternatively, they might move directly from the marrow into the joint cavity. Vascular channels that connect the bone marrow to the SM have been identified in rats with collagen-induced arthritis (46). It remains to be seen if similar anatomic structures exist in humans and are also operating in nonpathologic conditions. The origin from pericytes represents an alternative, since vascular pericytes have been reported to have osteochondral potential (47).

The availability of MSCs in adult human SM opens important therapeutic options in regenerative medicine. Arthroscopy is a routine procedure for traumatic and nontraumatic joint conditions. A small SM biopsy represents an easily accessible source of autolo- gous MSCs in the context of an explorative or therapeutic arthroscopy. These cells can be subsequently used for the regeneration/repair of skeletal tissues. The preservation of their biologic characteristics after storage in liquid nitrogen guarantees a versatile availability of autologous progenitor cells, even after years.

Joint surface defect repair represents a potential application. The most widely used technique, autologous chondrocyte transplantation (48), is limited by the availability of cells, particularly in elderly individuals, and by the well-known dedifferentiation events associated with chondrocyte expansion (49). In addition, the cartilage biopsy necessary for autologous chondrocyte preparation itself represents an additional injury, and may be detrimental to the surrounding healthy articular cartilage (50). The SM may be an optimal alternative source of chondrogenic cells for joint surface defect repair.

\section{ACKNOWLEDGMENTS}

We thank J. Bellemans (Department of Orthopedics, Katholieke Universiteit, Leuven, Belgium) for providing synovial membrane samples, S. Tejpar (Centrum Menselijke Erfelijkheid, Katholieke Universiteit, Leuven, Belgium) for providing human dermal fibroblasts, and F. P. Cantatore (University of Bari, Bari, Italy) for providing human trabecular osteoblasts. Special thanks are also due to the people working in the mortuary of the Katholieke Universiteit Leuven.

\section{REFERENCES}

1. Fuchs E, Segre JA. Stem cells: a new lease on life. Cell 2000;100: $143-55$.

2. Pittenger MF, Mackay AM, Beck SC, Jaiswal RK, Douglas R, Mosca JD, et al. Multilineage potential of adult human mesenchymal stem cells. Science 1999;284:143-7.

3. Asahara T, Murohara T, Sullivan A, Silver M, van der Zee R, Li $\mathrm{T}$, et al. Isolation of putative progenitor endothelial cells for angiogenesis. Science 1997;275:964-7.

4. Asahara T, Masuda H, Takahashi T, Kalka C, Pastore C, Silver M, et al. Bone marrow origin of endothelial progenitor cells responsible for postnatal vasculogenesis in physiological and pathological neovascularization. Circ Res 1999;85:221-8.

5. Ferrari G, Cusella-De Angelis G, Coletta M, Paolucci E, Stornaiuolo A, Cossu G, et al. Muscle regeneration by bone marrowderived myogenic progenitors. Science 1998;279:1528-30.

6. Gussoni E, Soneoka Y, Strickland CD, Buzney EA, Khan MK, Flint AF, et al. Dystrophin expression in the mdx mouse restored by stem cell transplantation. Nature 1999;401:390-4.

7. Petersen BE, Bowen WC, Patrene KD, Mars WM, Sullivan AK, Murase N, et al. Bone marrow as a potential source of hepatic oval cells. Science 1999;284:1168-70.

8. Theise ND, Nimmakayalu M, Gardner R, Illei PB, Morgan G, Teperman L, et al. Liver from bone marrow in humans. Hepatology 2000;32:11-6.

9. Eglitis MA, Mezey E. Hematopoietic cells differentiate into both microglia and macroglia in the brains of adult mice. Proc Natl Acad Sci U S A 1997;94:4080-5.

10. Kopen GC, Prockop DJ, Phinney DG. Marrow stromal cells 
migrate throughout forebrain and cerebellum, and they differentiate into astrocytes after injection into neonatal mouse brains. Proc Natl Acad Sci U S A 1999;96:10711-6.

11. Nakahara H, Goldberg VM, Caplan AI. Culture-expanded human periosteal-derived cells exhibit osteochondral potential in vivo. J Orthop Res 1991;9:465-76.

12. O'Driscoll SW, Recklies AD, Poole AR. Chondrogenesis in periosteal explants: an organ culture model for in vitro study. J Bone Joint Surg Am 1994;76:1042-51.

13. De Bari C, Dell'Accio F, Luyten FP. Human periosteum-derived cells maintain phenotypic stability and chondrogenic potential throughout expansion regardless of donor age. Arthritis Rheum 2001;44:85-95.

14. Baroffio A, Hamann M, Bernheim L, Bochaton-Piallat ML, Gabbiani G, Bader CR. Identification of self-renewing myoblasts in the progeny of single human muscle satellite cells. Differentiation 1996;60:47-57.

15. Jackson KA, Mi T, Goodell MA. Hematopoietic potential of stem cells isolated from murine skeletal muscle. Proc Natl Acad Sci U S A 1999;96:14482-6.

16. Dimri GP, Lee X, Basile G, Acosta M, Scott G, Roskelley C, et al. A biomarker that identifies senescent human cells in culture and in aging skin in vivo. Proc Natl Acad Sci U S A 1995;92:9363-7.

17. Kim NW, Piatyszek MA, Prowse KR, Harley CB, West MD, Ho PL, et al. Specific association of human telomerase activity with immortal cells and cancer. Science 1994;266:2011-5.

18. Harrison ET Jr, Luyten FP, Reddi AH. Osteogenin promotes reexpression of cartilage phenotype by dedifferentiated articular chondrocytes in serum-free medium. Exp Cell Res 1991;192: $340-5$.

19. Jaiswal N, Haynesworth SE, Caplan AI, Bruder SP. Osteogenic differentiation of purified, culture-expanded human mesenchymal stem cells in vitro. J Cell Biochem 1997;64:295-312.

20. Wakitani S, Saito T, Caplan AI. Myogenic cells derived from rat bone marrow mesenchymal stem cells exposed to 5-azacytidine. Muscle Nerve 1995;18:1417-26.

21. Goldstein S. Replicative senescence: the human fibroblast comes of age. Science 1990;249:1129-33.

22. Marinova-Mutafchieva L, Taylor P, Funa K, Maini RN, Zvaifler NJ. Mesenchymal cells expressing bone morphogenetic protein receptors are present in the rheumatoid arthritis joint. Arthritis Rheum 2000;43:2046-55.

23. Sen M, Lauterbach K, El-Gabalawy H, Firestein GS, Corr M, Carson DA. Expression and function of wingless and frizzled homologs in rheumatoid arthritis. Proc Natl Acad Sci U S A 2000;97:2791-6.

24. Dell'Accio F, De Bari C, Luyten FP. Molecular basis of joint development. Jpn J Rheumatol 1999;9:17-29.

25. Haziot A, Chen S, Ferrero E, Low MG, Silber R, Goyert SM. The monocyte differentiation antigen, CD14, is anchored to the cell membrane by a phosphatidylinositol linkage. J Immunol 1988;141: $547-52$.

26. Shalaby F, Ho J, Stanford WL, Fischer KD, Schuh AC, Schwartz $\mathrm{L}$, et al. A requirement for Flk1 in primitive and definitive hematopoiesis and vasculogenesis. Cell 1997;89:981-90.

27. Rosenberg L. Chemical basis for the histological use of safranin $O$ in the study of articular cartilage. J Bone Joint Surg Am 1971;53: 69-82.

28. Blasco MA, Gasser SM, Lingner J. Telomeres and telomerase. Genes Dev 1999;13:2353-9.

29. Yamanishi Y, Hiyama K, Maeda H, Ishioka S, Murakami T, Hiyama E, et al. Telomerase activity in rheumatoid synovium correlates with the mononuclear cell infiltration level and disease aggressiveness of rheumatoid arthritis. J Rheumatol 1998;25: 214-20.

30. Yudoh K, Matsuno H, Nezuka T, Kimura T. Different mechanisms of synovial hyperplasia in rheumatoid arthritis and pig- mented villonodular synovitis: the role of telomerase activity in synovial proliferation. Arthritis Rheum 1999;42:669-77.

31. Bodnar AG, Ouellette M, Frolkis M, Holt SE, Chiu CP, Morin $\mathrm{GB}$, et al. Extension of life-span by introduction of telomerase into normal human cells. Science 1998;279:349-52.

32. Iwata H, Ono S, Sato K, Sato T, Kawamura M. Bone morphogenetic protein-induced muscle- and synovium-derived cartilage differentiation in vitro. Clin Orthop 1993;296:295-300.

33. Nishimura K, Solchaga LA, Caplan AI, Yoo JU, Goldberg VM, Johnstone B. Chondroprogenitor cells of synovial tissue. Arthritis Rheum 1999;42:2631-7.

34. O'Driscoll SW, Ito Y, Fitzsimmons JS. Age-related decrease in chondrogenic potential correlates with a decrease in chondrocyte precursor pool size [abstract]. Trans Orthop Res Soc 2000;25:935.

35. Maurice H, Crone M, Watt I. Synovial chondromatosis. J Bone Joint Surg Br 1988;70:807-11.

36. Rosen PS, Pritzker KPH, Greenbaum J, Holgate RC, Noyek AM. Synovial chondromatosis affecting the temporomandibular joint: case report and literature review. Arthritis Rheum 1977;20: $736-40$.

37. Fujita S, Iizuka T, Yoshida $H$, Segami N. Transforming growth factor and tenascin in synovial chondromatosis of the temporomandibular joint: report of a case. Int J Oral Maxillofac Surg 1997;26:258-9.

38. Van Beuningen HM, van der Kraan PM, Arntz OJ, van den Berg WB. Transforming growth factor- $\beta 1$ stimulates articular chondrocyte proteoglycan synthesis and induces osteophyte formation in the murine knee joint. Lab Invest 1994;71:279-90.

39. Van Beuningen HM, Glansbeek HL, van der Kraan PM, van den Berg WB. Differential effects of local application of BMP-2 or TGF- $\beta 1$ on both articular cartilage composition and osteophyte formation. Osteoarthritis Cartilage 1998;6:306-17.

40. Van Beuningen HM, Glansbeek HL, van der Kraan PM, van den Berg WB. Osteoarthritis-like changes in the murine knee joint resulting from intra-articular transforming growth factor- $\beta$ injections. Osteoarthritis Cartilage 2000;8:25-33.

41. Muraglia A, Cancedda R, Quarto R. Clonal mesenchymal progenitors from human bone marrow differentiate in vitro according to a hierarchical model. J Cell Sci 2000;113:1161-6.

42. Gurdon JB. A community effect in animal development. Nature 1988;336:772-4.

43. Cossu G, Kelly R, Di Donna S, Vivarelli E, Buckingham M. Myoblast differentiation during mammalian somitogenesis is dependent upon a community effect. Proc Natl Acad Sci U S A 1995;92:2254-8.

44. Gilbert JE. Current treatment options for the restoration of articular cartilage. Am J Knee Surg 1998;11:42-6.

45. Zvaifler NJ, Marinova-Mutafchieva L, Adams G, Edwards CJ, Moss J, Burger JA, et al. Mesenchymal precursor cells in the blood of normal individuals. Arthritis Res 2000;2:477-88.

46. Nakagawa S, Toritsuka Y, Wakitani S, Denno K, Tomita T, Owaki $\mathrm{H}$, et al. Bone marrow stromal cells contribute to synovial cell proliferation in rats with collagen induced arthritis. J Rheumatol 1996;23:2098-103.

47. Doherty MJ, Ashton BA, Walsh S, Beresford JN, Grant ME, Canfield AE. Vascular pericytes express osteogenic potential in vitro and in vivo. J Bone Miner Res 1998;13:828-38.

48. Brittberg M, Lindahl A, Nilsson A, Ohlsson C, Isaksson O, Peterson L. Treatment of deep cartilage defects in the knee with autologous chondrocyte transplantation. N Engl J Med 1994;331:889-95.

49. Benya PD, Shaffer JD. Dedifferentiated chondrocytes reexpress the differentiated collagen phenotype when cultured in agarose gels. Cell 1982;30:215-24.

50. Lee CR, Grodzinsky AJ, Hsu HP, Martin SD, Spector M. Effects of harvest and selected cartilage repair procedures on the physical and biochemical properties of articular cartilage in the canine knee. J Orthop Res 2000;18:790-9. 